\title{
On the Existing Problems and Improvement methods of Teaching Analog Circuit
}

\author{
Heng WANG ${ }^{1, a}$ \\ ${ }^{1}$ School of Electronics and Information Engineering, Jingchu University of Technology \\ Jingmen 448000,China \\ a wanghengwh@126.com
}

Keywords: Analogue circuit; teaching; problems; methods

Abstract. Combined with the teaching experience of analog circuit, analyze the existing problems of teaching analog circuit, and come up with methods to improve the quality of this course.

\section{Introduction.}

With the increasing emergence and development of new theory and new technology of analog circuit, it is quite crucial for the students to learn this course well in order to deeply study the knowledge of electronic technology, adapt to the working demand and finally achieve the goal of training the professionals. Through the study of this course, students can fully grasp the basic knowledge, basic theory and basic method of analog circuit. They can analyze and calculate the general electronic circuits from the perspective of engineering practice. They can also have a strong ability to interpret blueprints and a simple electronic circuit design capacity. During the learning process of analog circuit, a lot of students feel it is hard to start and the content is boring. Teachers also complain it is difficult to teach this course. This paper combines with the personal teaching experience, analyzing the existing problems and exploring methods to improve the quality of teaching.

\section{Existing problems of Analog circuit Course}

Nowadays, most of the colleges, which have the major of electronic information, have the analog circuit course. Nationally, its coverage is quite wide. In addition to the analog electronics course, $\mathrm{RF}$ and circuit should also belong to the analog circuit course. In the curriculum of communication, it is self-contained and its time span is long. Because this course has the experiment parts, its theory part and experiment teaching parts are complementary. However, during the whole teaching process, it exits some problems. They mainly reflected in the textbooks are lagging behind. This course has little time for the teachers to explain, so most of the teachers pay much attention to the aspect of basic theoretical knowledge, rather than the experimental part of the contents of the application.

\section{a. Textbook content is relatively lagging behind}

The gap between teaching material and practical application is relatively large. According to the current development of the semiconductor industry, many of the devices are no longer the original integration that we are talking about. The current textbooks do not refer to this area too much. A great number of domestic materials are in favor of the transistor. Analog circuit is a technical course, which is very practical and has few parts about IC System Design and Application Research. Therefore, students have a kind of feeling that do not understand how to use.

\section{b. Pay More Attention to Theory and Less Attention to Practice}

Traditional teaching model is based on the theory, supplemented by the simple and confirmatory experiment. Teachers often give a large number of theoretical knowledge to students. Even if there is some experimental parts, it is the proof of some knowledge. In this way, students cannot systematically grasp the skills. Through a semester's study, students are not able to analyze the simple circuit, let alone the circuit design. Because students cannot integrate the theory with practice, this makes the theory away from the practice. Then it prevents the subsequent professional 
studies. Students may lose the interest to this course.

\section{c. Inadequate School Hours}

In order to reduce the school hours, many schools try to use less school hours. However, little school hours give teachers a great deal of pressure. The pressure is how to teach students during limited school hours. The course of analog circuit has a great number of basic theories and basic concepts with multiple levels. These require students mastering knowledge systematically. During the teaching, teachers should connect the knowledge in order to avoid the blind point in the following studies. However, because of the limited school hours, it is difficult for the teachers to cover all the knowledge and bullet points. In this way, many students feel the course of analog circuit is hard to learn and this will destroy their interest. Finally, this affects the quality of teaching. In addition, from the perspective of electronic technology, the level of difficulty to study analog between digital is different. There is an old feeling that many systems are digital and mobile phone analog is also a pure digital system. They feel analog circuit is no long useful.

\section{Methods to Improve the Quality of the Course}

In the limited school hours, the key is to conveying the message of the real analog circuit knowledge. Then, during the class it requires teachers arranging the teaching content flexibly and integrating the theory with practice. Especially when teachers teach theories, it is essential to pay attention to the teaching strategies and teaching methods.

\section{a. Students Play the Main Role in the Teaching}

Teaching and learning are the most import fundamental factors. In order to finish the teaching tasks and achieve the teaching goals, we must give full play to the role of both sides, especially the role that students play in the teaching. Therefore, during the school hours, teachers not only educate knowledge and skills but also inspire and mobilize the consciousness of students so that they are able to learn by themselves. According to the complexity of this course, students can learn from the basic knowledge and the try to analyze electronic circuits. Therefore, students can be more comfortable to learn this course.

\section{b. Define the Course and Stimulate the Interest}

Most of the content of analog circuit is to introduce amplifier circuit. First of all, it is crucial to let the students have an overall concept and let them understand the role of amplifier circuit in the entire electronic system. Besides, this idea should be mentioned repeatedly in the every chapter in order to deepen the understanding. Secondly, in the lectures, there are a lot of aspects that need to contact the engineering applications. Selecting the types of electronic equipment and electronic system as the examples, it is useful to apply these instances so that students could replicate. For example, For example, sensor conditioning IC (system), sensor conditioning IC (system), sensor conditioning IC (system) and so on. In this way, it will stimulate the students' interest.

\section{c. Pay Attention to the Ability to Analyze and Solve the Problems}

In the teaching, teachers should not only let the students be able to acquire the knowledge but more importantly is to make the students learn to analyze and solve problems. In the traditional education concept, we regarded the knowledge as centers and emphasized the importance of book knowledge. All of these lead to the ignoring the practical experience and influence the training of professionals. Therefore, when teaching, teachers should focus on the development and improvement of student's ability. For example, teachers should try hard to introduce the connection between analog circuit and other course, its use in our everyday appliances application and its future development direction. The reason why students feel difficult to learn is that their ability to apply the basic knowledge is quite poor. Such as, they do not know how to utilize circuit theory, so teachers should know how to guide them in order to grasp the particularity of electronic circuits and then combine with engineering application characteristics, then use the prior knowledge of the 
circuit for qualitative or quantitative analysis.

\section{d. Focus on the Connection between Analog Circuits with Previous Course}

During the process of teaching analog circuits, we often use basic theory to analyze and solve problems. It has a nature link with electronic theory. General speaking, circuit theory is often studied before class. Although the time interval is not two long, most of the students have the blurred memory. Therefore, it is rather necessary for the review. At the beginning of the class, teachers should take some time to explain the relationship between the two courses, especially the introduction to the importance of the course of circuit theory.

\section{e. Note the Explanation of the Basic Concepts}

Besides, teachers should highlight the basic concepts. For example, the study of PN junction unidirectional conductivity, FET and bipolar transistor comparison study. These two studies emphasize the difference of linear and non-linear and DC path and communication pathways.

\section{f. Use the method of Basic Circuit and Fundamental Analysis}

Various discrete components of the electronic circuit are made up of basic circuit and stable-bias circuit and the method of AC analysis is one of the most basic ways. Most of the IC is made up of basic circuit-integrated op amp. The analysis methods of virtual short and false break are the most basic ways. It should be noted that these methods must be stressed repeatedly. For instance, every new circuits should let the students know how to find the bias circuit and walk paths of AC and DC. Basic on these, students can learn the special components and special effects. In this way, students can enhance their foundation so that learn this subject easily.

\section{g. Reduce the Degree of Difficulty}

When learning the new knowledge, students may feel very hard to grasp if they do not pay attention to the intrinsic link between the old one and the new one. If they have the first return, then they can feel better to master the new knowledge. For example, when students learn a new circuit, it is necessary to not reveal everything. However, on the basis of old circuit, then students may feel that it is not a new one. It is just a change of the old one. At the same time, they feel very familiar. In this way, it improves the ability to withstand and acceptance. Concerning to the more difficult knowledge points, we can divide them into a few parts to change the big one into the small one. For example, the judgment of negative feedback analog circuit is a main difficulty lesson to introduce three ways to judge, that is the nature of the sampling method, comparative method. These four configurations need to be separated. If we talk about these in one class hour, then it is difficult to do and students may mix them up. As the result, students feel confused and not learn well. As a matter of fact, we can put them apart. Teachers should finish a judgment, then let the students do some practice. Finally, students can master them correctly and establish a solid foundation to these concepts so that they do not feel confused. In this way, the difficulties are been overcame.

\section{h. Highlight Practice and Learn from Every Aspects}

From the point of view of application and practice, teachers should apply multimedia teaching and increase the school hours. They should let the students know the practical circuits as many as possible so that it can destroy the fear that most students have. What's more, teachers can combine the teaching content and do some experiments so that it can fully develop the potential of the students' initiative learning. Let the students have a better access to the chip and do some hands-on designs; teachers can make some adjustments on the curriculum. From the perspective of courseware, teachers can still do some work. After the SOC, many chips are systems. But students have little knowledge about chips and semiconductor. So, it is quite necessary to start with lower levels. National Undergraduate Electronic Design Contest provides a good platform to the students' hands-on opportunities. The key is to having some adjustments in the architecture structure. 


\section{i. Enrich and Improve the Teaching Methods}

The course of analog circuit is abstract and has strong theoretical characteristics. The use of multimedia courseware can improve the efficiency. To avoid the boring study process, teachers can use vivid languages and associated with the inherent knowledge of the internal logic and science. For example, in order to explain the complex PN junction hole and electron drift and recombination process, teachers can adopt the animation. At the same time, teachers can let the students involve in the class education because it can motivate the atmosphere.

\section{Conclusion}

According to the practice, the teaching of analog circuit has some difficulties because it involves both theory and practice. Then, it requires teachers make conclusions during the teaching process, improve the teaching methods and do some research in order to improve the quality of education.

\section{Reference}

[1] Zhou Lingling. On the Analog Teaching Experience [J]. Electronic World, 2008(3)

[2] Liu Lili. Teaching Experience and Reform of Analog Circuit [EB/OL].http://www.studa.n et/xueke/100601/15561780-2.html, 2010(6)

[3] Cheng $\mathrm{Yu}[\mathrm{J}]$. Misunderstanding and Reform of Analog Circuit Teaching 2002,(2)

[4] Zhu Zhenrong. Application of Multimedia Technology in Teaching [J]China Technology Education, 1998,(8)

[5]Discussion of the teaching reform about the course of Analog Circuits LUO Hua,2010(6) 